\title{
Anti-inflammatory effect of Eucommia Chlorogenic Acid (ECA) on adjuvant-induced arthritis rats and its effect on autophagy related pathway
}

\author{
Chen LAN-FANG ${ }^{1 *}$ (D), Xuan DAN ${ }^{1}$, Sheng JUN ${ }^{1}$, Qiang FU-YONG ${ }^{1}$, Wang XIAO-WAN ${ }^{1}$, Xu LIANG $^{1}$
}

\begin{abstract}
Observation ECA's treatment effects in Adjuvant arthritis rats and relative mechanisms. The rat model of arthritis was established by subcutaneous injection of $0.2 \mathrm{~mL}$ Freund's complete adjuvant. After model success, giving different ECA concentrations $(25 \mathrm{mg} / \mathrm{kg}, 50 \mathrm{mg} / \mathrm{kg}$ and $100 \mathrm{mg} / \mathrm{kg}$ ) to rats by ig methods and continued to 28 days. Measuring thymus and spleen index; observation histopathological morphology of rat joint by HE and Masson staining, and Inflammatory cells, synovial hyperplasia, oochas score and degree of fibrosis were detected semi quantitatively. The relative gene and protein expressions were measured by RT-PCR and Western blot. Compared with Normal group, Inflammatory cells, synovial hyperplasia, fibrosis and oochas score increased significantly in Model group ( $\mathrm{P}<0.01$, respectively); COX-1, COX-2, TNF- $\alpha$, IL-1 $\beta$, IL- 6 and IL- 17 mRNA expression were significantly up-regulation $(\mathrm{P}<0.01)$; AMPK, Beclin 1 and ATG12 mRNA and protein expressions were significantly down-regulation $(\mathrm{P}<0.01$, respectively). Compared with Model group, The inflammatory cells, the degree of fibrosis, the proliferation of synovial tissue and OOCHAS score decreased significantly in Middle and High groups $(\mathrm{P}<0.01$, respectively); Thymus index significantly depressed in Low, Middle and High groups $(\mathrm{P}<0.01$, respectively); spleen index were significantly down-regulation in Middle and High groups $(\mathrm{P}<0.05$ or $\mathrm{P}<0.01)$; COX-2, TNF- $\alpha$ and IL-17 mRNA expression was significantly down-regulation $(\mathrm{P}<0.05)$, IL-1 $\beta$ and IL- 6 mRNA expression were significantly depressed in Middle and High groups $(\mathrm{P}<0.05$ or $\mathrm{P}<0.01)$; AMPK, Beclin1, LC3-II, ATG5 and ATG7 mRNA expressions were significantly up-regulation in Middle and High groups $(\mathrm{P}<0.05$ or $\mathrm{P}<0.01)$; mTOR gene expression was significantly down-regulation $(\mathrm{P}<0.05)$, ATG12 mRNA expression was significantly up-regulation $(\mathrm{P}<0.01)$ in High group; AMPK, Beclin1, LC3-II, ATG5 and ATG7 protein expressions were significantly increased in High group $(\mathrm{P}<0.05$ or $\mathrm{P}<0.01)$, mTOR protein expression were significantly down-regulation and ATG12 protein expression were significantly up-regulation in Low, Middle and High groups $(\mathrm{P}<0.05$ or $\mathrm{P}<0.01$, respectively). ECA can inhibit the inflammatory response in adjuvant arthritis rats, and its mechanism may be related to promoting autophagy of synovial cells.
\end{abstract}

Keywords: ECA; autophagy; inflammatory; rheumatoid arthritis.

Practical Application: Eucommia Chlorogenic Acid (ECA) had effects to improve adjuvant-induced arthritis.

\section{Introduction}

Rheumatoid arthritis (RA) is a typical chronic inflammation characterized by systemic autoimmune abnormalities (Weyand \& Goronzy, 2021). The major clinical features of RA include synovitis, cartilage injury and symmetrical joint injury (Wasserman, 2011). According to previous research, in RA patients, owing to the insufficient glycolytic enzymes in vivo, there may be a low glycolytic flux of T cells and deficiency of ATP (Silva et al., 2019). Subsequently, due to the decreased ratio of AMP and ATP, there may be an activation in the autophagy related signal transduction pathway, accompanied by abnormal expressions of genes and proteins in this pathway. Simultaneously, adenosine monophosphate (AMP)-activated protein kinase (AMPK) and mammalian target of rapamycin (mTOR) in this pathway are recognized to be the key genes and proteins to initiate autophagy pathway. In view of the above content, it is suggested that abnormality in the autophagy pathway in RA patients may be one of the causes inducing the pathogenesis of RA.
Despite the presence of various RA models, the most classic is the adjuvant-induced arthritis (AA) rat model induced by Freund's complete adjuvant (CFA) (Weng et al., 2021). Considering that rats in the AA model share similarities to those of RA patients, the proposed rat model was selected for experiment in this study.

Eucommia Ulmoides Oliv is a traditional Chinese herbal medicine. Its extract, especially chlorogenic acid in Eucommia Ulmoides Oliv (ECA), has been demonstrated by relevant studies to have antioxidant effect in vivo and in vitro, can regulate nutrient metabolism and possess immune function (Murakami et al., 2018; Hao et al., 2016; Teng et al., 2021). Chlorogenic acid and other polyphenols are known as the "Seventh Nutrients". Since its chemical structure was first determined in 1947, chlorogenic acid has been clarified to have a series of physiological activities, as supported by a large number of studies. ECA is the main active component of Eucommia Ulmoides Oliv, and the latter traditional Chinese medicine has been confirmed to have a positive effect on the treatment of RA (Xing et al., 2020; Wang et al., 
2018). Recent studies have reported a strong anti-inflammatory activity of ECA (Chen et al., 2021; Zhou et al., 2021; Jiang et al., 2021). However, there is a lack of related report concerning the correlation between the anti-inflammatory effect of ECA and autophagy related genes. Accordingly, the present study was carried out based on ECA intervention of the established AA model in rats to explore the anti-inflammatory effect of ECA on AA rats and its effects on autophagy related pathways.

\section{Materials and methods}

\subsection{Drugs, reagents and instruments}

ECA (Xi'an Tianrui Biotechnology Co., Ltd, Xi'an, China); rabbit anti-rat AMPK monoclonal antibody, rabbit anti-rat mTOR polyclonal antibody, rabbit anti-rat Beclin1 polyclonal antibody and rabbit anti-rat light chain 3-II (LC3-II) polyclonal antibody (Abcam, UK); rabbit anti-rat autophagy related gene 5 (ATG5), ATG7 and ATG12 polyclonal antibodies (ABclonal Technology, Wuhan, China); horse-radish peroxidase-labeled goat anti-rabbit IgG antibody, as well as primers of GAPDH, interleukin 6 (IL-6), IL-1 $\beta$, IL-17, tumor necrosis factor $\alpha$ (TNF- $\alpha$ ), cyclooxygenase 1 (COX-1), COX-2, AMTK, mTOR, Beclin1, LC3-II, ATG5, ATG7 and ATG-12 primers (Beijing Dingguo Changsheng Biotechnology Co., Ltd); reverse transcription cDNA kit and high-purity total RNA rapid extraction kit (BioTake, USA); and BCA protein concentration assay kit (Shanghai Yisheng Bio-Technology Co., Ltd.).

Microplate Reader (680, Bio-Rad, USA); Gel Imaging System (E-Gellmager, Thermo Fisher Scientific, USA); PCR instrument (Master cycler X50, Eppendorf, Germany); electrophoresis apparatus (JY200C, Shanghai Kehuai Instrumentation Co., Ltd); microtome (RM2235) and paraffin embedding station (EG1150, Leica, Germany); chemiluminescence imaging system (MG8000, Thmorgan Biotechnology Co., Ltd.); toe volume measuring instrument (PV-200, Chengdu Taimeng Co., Ltd.).

\subsection{Animals, AA model establishment and grouping}

The experimental animals were 50 6-7-week-old male Wistar rats (Changchun Yisi Experimental Animal Technology Co., Ltd.), with a body mass of 200 210 g. Experimental animals were reared in the laboratory animal room under SPF conditions, with room temperature of $24^{\circ} \mathrm{C}$ and relative humidity of $45 \% \sim 55 \%$. All the rats were fed adaptively for one week prior to the experiment. The experimental design and operation were reviewed and approved by the Animal Ethics Committee of Yijishan Hospital Affiliated to Wannan Medical College.

After one week of adaptive feeding, rats were randomly divided into 5 groups, with 10 rats in each group, including the Normal group, Model group, Model+ECA $25 \mathrm{mg} / \mathrm{kg}$ group (Low), Model+ECA50 mg/kg group (Middle) and Model+ECA100 mg/ $\mathrm{kg}$ group (High). Taking the day of modeling as the experimental day 0 (D0), rats in the Normal group were injected with $0.2 \mathrm{~mL}$ normal saline by subcutaneous syringe on the footpad of right hindfoot, and the other 40 rats were injected with $0.2 \mathrm{~mL}$ CFA (Weng et al., 2021). After injection for $8 \mathrm{~h}$, the modeling was successful when the swelling degree of inflamed feet of rats was greater than $0.8 \mathrm{~mL}$. From D1, rats in Normal and Model groups were given normal saline through intragastric (ig) administration, and rats in other groups were given corresponding drugs via ig administration (once a day, for 28 days). The body mass of D0 and D28 rats was measured to observe and record the changes of body mass.

\subsection{Measurement of the thymus and spleen indexes of $A A$ rats}

One hour after the last administration, rats from the above groups (section 1.2) were weighed, and given $25 \%$ urethane $(4 \mathrm{mg} / \mathrm{kg})$ through intraperitoneal injection (ip) for anesthesia. Rats were then killed for the immediate collection of thymus and spleen. After washing with normal saline, the collected thymus and spleen were wiped with filter paper and weighed to calculate the indexes of thymus and spleen (van Eden et al., 2001). Thymus or spleen index $=$ Thymus or spleen mass (g)/ body mass $(\mathrm{g}) \times 100 \%$.

\subsection{Observation of pathological changes of joint tissue in $A A$ rats by HE staining}

The ankle joint of right hindfoot of rats in each group was fixed with $10 \%$ neutral formaldehyde and decalcified with 10\% EDTA. The decalcified solution was replaced once every 4 days and the tissues were dehydrated for $24 \mathrm{~h}$. following paraffin embedding, sections were prepared into serial sections of $5 \mu \mathrm{m}$ in thickness for HE staining. The pathological morphological changes of rat joints were observed under light microscope, associated with pathological scoring, followed by semi-quantitative detection of the inflammatory cell, synovial hyperplasia and OOCHAS scores (Custers et al., 2007). Inflammatory cell scoring criteria: 0 , none; 1 point, sparse and scattered; 2 points, relatively dense; and 3 points, massive. Synovial hyperplasia scoring criteria: 0 , none; 1-point, single layer; 2 points, 2 layers; and 3 points, 3 layers. OOCHAS score $=$ Grades of articular cartilage injury depth and corresponding tissue response (grade $0 \sim 6) \times$ Stages for the range of articular cartilage injury (stage $0 \sim 4$ ); Grade scoring criteria: grade 0: complete articular surface and cartilage; grade 1: surface integrity; grade 2: surface discontinuity; grade 3: vertical crack; grade 4: erosion; and grade 5: defect; grade 6: deformation; and stage scoring criteria: stage 0 : no inflammation; stage 1: the damage area of $<10 \%$ of the sample area; stage 2: the damage area of between $10 \% \sim 25 \%$ of the sample area; stage 3 : the damage area of between $25 \% \sim 50 \%$ of the sample area; and stage 4 : the damage area of $>50 \%$ of the sample area.

\subsection{Observation of the changes of joint fibrosis in AA rats by Masson staining}

The collagen fibers in joint tissue were stained and observed to evaluate the changes of articular cartilage. Paraffin-embedded sections were dewaxed and stained with prepared Weigert's iron hematoxylin for $5 \mathrm{~min}$, followed by differentiation using acid acetic acid solution. After that, sections were blued was performed by using Masson bluing solution; washed with distilled water for $1 \mathrm{~min}$; and stained with fuchsin staining solution for $6 \mathrm{~min}$. Sections were then washed with the prepared weak acid 
solution (distilled water - weak acid solution: 2:1) in advance for $1 \mathrm{~min}$; phosphomolybdic acid solution for $1 \mathrm{~min}$; and weak acid solution for $1 \mathrm{~min}$. After that, the processed sections were stained with aniline blue staining solution for $1 \mathrm{~min}$; washed with weak acid solution for $1 \mathrm{~min}$; followed by dehydration, transparent processing with xylene, and sealing with neutral gum.

\subsection{Detection of the mRNA expression levels of} inflammatory related factors and autophagy related genes in synovium of footpad joint of $A A$ rats by RT-PCR

With the reverse transcribed cDNA as the template, PCR amplification was performed with initial denaturation at $94^{\circ} \mathrm{C}$ for $3 \mathrm{~min}$, followed by 20 cycles of denaturation at $94^{\circ} \mathrm{C}$ for $30 \mathrm{~s}$, annealing at $65{ }^{\circ} \mathrm{C}$ for $30 \mathrm{~s}$ and extension at $72{ }^{\circ} \mathrm{C}$ for $1 \mathrm{~min}$, and full extension at $72{ }^{\circ} \mathrm{C}$ for $10 \mathrm{~min}$. The next steps were spot sampling, electrophoresis at $100 \mathrm{~V}$ for 40 min using $2 \%$ agarose and Gelred reagent for $1 \mathrm{~h}$, followed by the observation of the amplified products using gel imaging analysis system. Semi-quantitative analysis of the mRNA expression of target gene was carried out, and data analysis was conducted based on the absorbance ratio of target gene band and GAPDH band. Table 1 shows the PCR primer sequences. The above experiments were repeated at least 3 times.

2.7 Detection of the protein expression levels of $A M P K$, mTOR, Beclin1, LC3-II, ATG5, ATG7 and ATG12 in synovium of footpad joint of $A A$ rats by Western blot

The synovial tissue of the inflamed foot of the right hindfoot of rats in each group was taken for the extraction of total protein by using the prepared lysis buffer, PMSF and phosphatase

Table 1. Sequence of primers for RT-PCR.

\begin{tabular}{|c|c|c|}
\hline Gene & Sequence $\left(5^{\prime}-3^{\prime}\right)$ & Length \\
\hline GAPDH & $\begin{array}{l}\text { F: GGCAAGTTCAACGGGACAG } \\
\text { R: GCCAGTAGACTCCACGACAT }\end{array}$ & $148 \mathrm{bp}$ \\
\hline TNF- $\alpha$ & $\begin{array}{l}\text { F: ATGTGGAACTGGCAGAGGAG } \\
\text { R: AGTAGACAGAAGAGCGTGGTG }\end{array}$ & $127 \mathrm{bp}$ \\
\hline IL-6 & $\begin{array}{l}\text { F: CCAACTTCCAATGCTCTCCTAAT } \\
\text { R: CGAGTAGACCTCATAGTGACCTT }\end{array}$ & $125 \mathrm{bp}$ \\
\hline IL-1 $\beta$ & $\begin{array}{c}\text { F: GGATGATGACCTGCTAGT } \\
\text { R: CACTTGTTGGCTTATGTTCTGTC }\end{array}$ & $148 \mathrm{bp}$ \\
\hline IL-17 & $\begin{array}{l}\text { F: CGCCGAGGCCAATAACTTTC } \\
\text { R: GGTTGAGGTAGTCTGAGGGC }\end{array}$ & $104 \mathrm{bp}$ \\
\hline COX-1 & $\begin{array}{l}\text { F: CCCGCCCCATCTAACATCTC } \\
\text { R: CCCCACATGGAGGAATAGGC }\end{array}$ & $234 \mathrm{bp}$ \\
\hline COX-2 & $\begin{array}{l}\text { F: GCCAGTATTAGCAGCAGGTATC } \\
\text { R: GCCGAAGAATCAGAATAGGTGTT }\end{array}$ & $121 \mathrm{bp}$ \\
\hline AMPK & $\begin{array}{l}\text { F: GTGGACACCCAAGCTGACTG } \\
\text { R: AAGCAAATCCCTTCACCCAA }\end{array}$ & $127 \mathrm{bp}$ \\
\hline mTOR & $\begin{array}{l}\text { F: CAGAGGTGTGGTTTGACCGA } \\
\text { R: CAGCATCAGGTTGGATGGGT }\end{array}$ & $148 \mathrm{bp}$ \\
\hline Beclin1 & $\begin{array}{l}\text { F: AACTCTGGAGGTCTCGCTCT } \\
\text { R: CGCCTTAGACCCCTCCATTC }\end{array}$ & $125 \mathrm{bp}$ \\
\hline LC3-II & $\begin{array}{l}\text { F: TCCCAAGAAACCTTCGGCTT } \\
\text { R: CCAGCACCCAAAAGAGCAAG }\end{array}$ & $104 \mathrm{bp}$ \\
\hline ATG5 & $\begin{array}{l}\text { F: TGTGATCCCGGTAGACCCAA } \\
\text { R: AAACCACACGTCTCGAAGCA }\end{array}$ & $234 \mathrm{bp}$ \\
\hline ATG7 & $\begin{array}{l}\text { F: GGCTTGTACCTCACCAGATCC } \\
\text { R: CTGTGGTTGCTCAGACGGT }\end{array}$ & $121 \mathrm{bp}$ \\
\hline ATG12 & $\begin{array}{l}\text { F: GCTGAAGGCTGTAGGAGACA } \\
\text { R: CATCCCCATGCCTGTGATTTG }\end{array}$ & $249 \mathrm{bp}$ \\
\hline
\end{tabular}


inhibitor working solution. BCA Quantitative analysis of the extracted protein was performed with BCA protein concentration determination kit. Following the preparation of the concentrating gel and separating gel (12\% SDS- polyacrylamide gel), $50 \mu \mathrm{g}$ protein was sampled for electrophoresed (at $80 \mathrm{~V}$ for $30 \mathrm{~min}$, and then at $100 \mathrm{~V}$ for $1.5 \mathrm{~h}$ ), followed by transferring to the PVDF membrane at $100 \mathrm{~V}$ for $1 \mathrm{~h}$. After sealing using $5 \%$ skimmed milk powder at room temperature, the primary antibody was added for overnight incubation at $4{ }^{\circ} \mathrm{C}$. Rabbit anti-rat AMPK, mTOR, Beclin-1, LC3-II, ATG5, ATG7, ATG12 and GAPDH antibodies were diluted with TBST (dilution ratio of 1: 1,000). With the recovery of the primary antibody and membrane washing with TBST for 3 times (10 min each), the secondary antibody of HRP labeled goat anti-rabbit IgG (dilution ratio of 1: 10,000) was supplemented for $1 \mathrm{~h}$ of incubation at room temperature. With another TBST washing for 3 times (10 min each), immunoassay was performed with enhanced chemiluminescence substrate kit. GAPDH was used as the internal reference protein. The integral absorbance of protein bands was analyzed quantitatively by Image J software. The relative expression level of the target protein was calculated based on the ratio of the integral absorbance of the target protein band to the internal reference band.

\subsection{Statistical analysis}

The experimental results were expressed by Mean \pm SD and statistically processed by Graphpad Prism 5 software. One-way analysis of variance was used for sample comparison between groups, and t-test for inter-group comparison. $\mathrm{P}<0.05$ meant that the difference was statistically significant.

\section{Results and discussion}

\subsection{Effect of ECA on body mass of AA rats}

As shown in Table 2, the body mass of rats in the Model was significantly decreased at D28 when compared with those in the Normal group $(\mathrm{P}<0.01)$. Meanwhile, compared with the Model group, rats in Middle and High groups showed obviously increased body mass $(\mathrm{P}<0.01)$, and the body mass of rats in High group was close to that in Normal group.

\subsection{Effect of ECA on thymus and spleen index in AA rats}

In relative to the Normal group, Model group revealed an obvious upregulation in thymus index $(\mathrm{P}<0.01$, Table 3$)$; while compared with the Model group, Low, Middle and High groups displayed an evident decrease in thymus index $(\mathrm{P}<0.01$, Table 3$)$. Besides, compared with the Normal group, Model group had a significant increase in spleen index $(\mathrm{P}<0.01)$; and compared with Model, Middle and High groups showed remarkably decreased spleen index of rats $(\mathrm{P}<0.01$, Table 3$)$.

\subsection{Effect of ECA on joint tissue of AA rats}

According to the results of HE staining (Figure 1), rats in the Normal group displayed no abnormality in the joint structure, cartilage lining, joint space and bone tissue morphology, with no inflammatory cell infiltration in synovium; while in the Model group, it was observed with significant abnormality in the joint tissue, obvious proliferation of the synovium, infiltration
Table 2. Effect of ECA on body mass of adjuvant arthritis (AA) model rats.

\begin{tabular}{lcc}
\hline \multirow{2}{*}{ Group } & \multicolumn{2}{c}{ Body mass/g } \\
\cline { 2 - 3 } & D0 & D28 \\
\hline Normal & $202.55 \pm 2.32$ & $240.25 \pm 3.36$ \\
Model & $204.17 \pm 1.86$ & $193.43 \pm 1.12^{\star *}$ \\
Low & $203.54 \pm 2.38$ & $194.45 \pm 3.41$ \\
Middle & $203.73 \pm 1.61$ & $217.79 \pm 1.10$ \\
High & $203.42 \pm 2.15$ & $237.27 \pm 1.19 \# \#$ \\
\hline
\end{tabular}

The day of modeling was taken as the 0 day of the experimentin (D0). Rats in normal control group were injected with $0.2 \mathrm{~mL}$ saline in the right hindfoot plantar subcutaneously,and the remaining 50 rats were injected with $0.2 \mathrm{~mL}$ complete Freund' $\mathrm{s}$ adjuvant (CFA). After $8 \mathrm{~h}$,the swelling of the inflamed foot of the rats was all greater than $0.8 \mathrm{~mL}$, and the modeling was considered successful. From D1, the normal control group and the model group was ig given saline, and the remaining groups of rats were ig given ECA $25,50,100 \mathrm{mg} / \mathrm{kg}$ once a day for $28 \mathrm{~d}$. The body mass of rats on D0 and D28 was recorded. Mean $\pm \mathrm{SD}, \mathrm{n}=10$. ${ }^{* *} \mathrm{P}<0.01$, compared with Normal group; $\#$ \# $<0.01$,compared with Model group.

Table 3. Effect of ECA on thymus and spleen index of AA model rats $($ Mean $\pm \mathrm{SD}, \mathrm{n}=10$ ).

\begin{tabular}{lll}
\hline \multicolumn{1}{c}{ Group } & Thymus index & Splenic index \\
\hline Normal & $0.180 \pm 0.023$ & $0.153 \pm 0.013$ \\
Model & $0.288 \pm 0.026^{* *}$ & $0.238 \pm 0.016^{* *}$ \\
Low & $0.192 \pm 0.010 \# \#$ & $0.205 \pm 0.017$ \\
Middle & $0.165 \pm 0.009 \# \#$ & $0.193 \pm 0.015^{\#}$ \\
High & $0.116 \pm 0.012^{\# \#}$ & $0.178 \pm 0.014 \# \#$ \\
\hline
\end{tabular}

Thymus index or spleen index $=$ Thymus mass or spleen mass $(\mathrm{g}) /$ body mass $(\mathrm{g}) \times 100$. ${ }^{*} \mathrm{P}<0.01$, compared with Normal group; $\# \mathrm{P}<0.05$; \#\# $<0.01$, compared with Model group.

of the inflammatory cells and dilation of the blood vessels. Further semi-quantitative joint pathological scoring indicated that the inflammatory cell score, synovial hyperplasia score and OOCHAS score were significantly increased in the Model group $(\mathrm{P}<0.01)$. Compared with the Model group, Low group showed no obvious improvement in the lesions; in the Middle group, the joint structure of rats basically returned to normal, the infiltration of inflammatory cells decreased, and the score of inflammatory cells decreased significantly $(\mathrm{P}<0.05)$; while rats in the High group showed significantly decrease of inflammatory cells in synovial tissue $(\mathrm{P}<0.01)$, obviously alleviated synovial tissue proliferation $(\mathrm{P}<0.01)$, evidently reduced cartilage and bone erosion, and notably decreased OOCHAS score $(\mathrm{P}<0.01)$.

\subsection{Effect of ECA on joint tissue fibrosis in AA rats}

In view of the results of Masson staining (Figure 2), in the Normal group, it was found the articular cartilage matrix and collagen fibers were stained in blue evenly, with gradual deepening towards the calcified layer, clear tide line and clear 



Figure 1. Effects of ECA on joint tissues of AA rats by HE staining $(200 \times) .{ }^{*} \mathrm{P}<0.01$, compared with Normal group; $\# \mathrm{P}<0.05$, \#\#P<0.01, compared with Model group.

boundary between cartilage and subchondral bone, besides, the compact bone and bone trabecula of subchondral bone were also stained in blue, and the bone collagen was stained in red. While in the Model group, the articular cartilage surface of rats was rough and lost, the superficial cartilage was denatured without staining, showing obvious fibrosis; and there were a large number of flame-like protrusion that were stained in red near the tide line, without staining of the bone trabeculae, and unclear display of the boundary between cartilage and subchondral bone. ECA intervention groups showed improved morphology of articular cartilage in CIA rats to varying degrees. Specifically, there was no rough surface or loss of the cartilage in the High group, and there was no degeneration, non-staining and fibrosis in the superficial cartilage, suggesting the best therapeutic outcome in the High group (Figure 2).

\subsection{Effect of ECA on the mRNA expression levels of inflammatory factors in synovium of footpad joint of $A A$ rats}

Compared with Normal group, Model group had highly increase in the mRNA expression levels of COX-1, COX-2, TNF- $\alpha$, IL- $1 \beta$, IL- 6 and IL-17 $(\mathrm{P}<0.05, \mathrm{P}<0.01$, Figure 3$)$. Furthermore, in relative to Model group, Low, Middle and High group revealed no obvious difference in COX-1 mRNA expression, Middle group had obviously decreased IL- $1 \beta$ mRNA expression $(\mathrm{P}<0.05$, Figure 3), and High group was found with notable reduction of the mRNA expression levels of IL-1 $\beta$, COX-2, TNF- $\alpha$ and IL-6 $(\mathrm{P}<0.05, \mathrm{P}<0.01$, Figure 3$)$.

\subsection{Effect of ECA on the mRNA expression levels of autophagy related factors in synovium of footpad joint of AA rats}

There were significantly decreased mRNA expressions of AMPK, Beclin1, LC3-II, ATG5, ATG7 and ATG12 $(\mathrm{P}<0.05$, $\mathrm{P}<0.01$ ), while obviously increased mRNA expression of $\mathrm{mTOR}$ in the Model group than those in the Normal group $(\mathrm{P}<0.01)$. Furthermore, compared with Model group, Middle group and High group were detected with remarkably increased mRNA expression levels of AMPK, Beclin1, LC3-II, ATG5 and ATG7 $(\mathrm{P}<0.05, \mathrm{P}<0.01)$; besides, mTOR mRNA expression was decreased significantly in High group $(\mathrm{P}<0.05)$, while the mRNA expression of ATG12 was highly increased in Middle and High groups $(\mathrm{P}<0.01$, Figure 4$)$. 

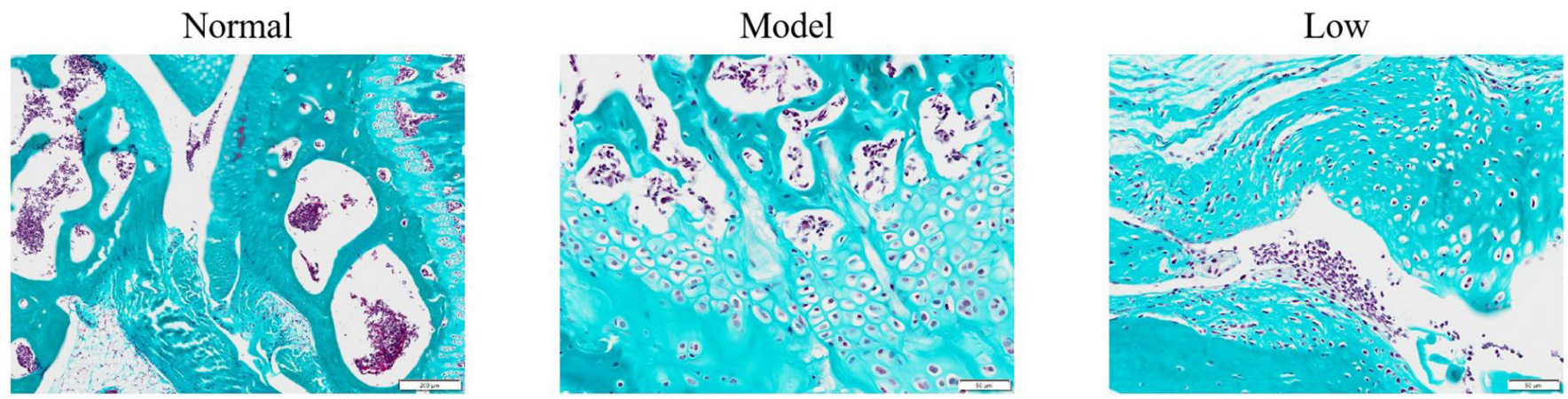

\section{Middle}



High



Figure 2. Effect of ECA on joint tissue fibrosis in AA rats by Masson staining (200x).


Figure 3. Effect of ECA on the mRNA expression levels of inflammatory factors in synovium of footpad joint of $\mathrm{AA}$ rats. ${ }^{* *} \mathrm{P}<0.01$, compared with Normal group; $\# \mathrm{P}<0.05$, \#\# $<<0.01$, compared with Model group. 


\subsection{Effect of ECA on the protein expression levels of autophagy related factors in synovium of footpad joint of} AA rats

In relative to the Normal group, Model group was found with significantly downregulated protein expressions of AMPK, Beclin1 and ATG12 ( $\mathrm{P}<0.05, \mathrm{P}<0.01$, Figure 5$)$, but obviously upregulated mTOR, LC3-II, ATG5 and ATG7 protein expressions
$(\mathrm{P}<0.05, \mathrm{P}<0.01$, Figure 5). Further comparison with Model group revealed that the protein expression levels of AMPK, Beclin1, LC3-II, ATG5 and ATG7 were significantly increased in the High group $(\mathrm{P}<0.05, \mathrm{P}<0.01$, Figure 5$)$; Low, Middle and High groups were detected with evidently decreased mTOR protein expression $(\mathrm{P}<0.05, \mathrm{P}<0.01$, Figure 5$)$, but highly increased ATG12 protein expression $(\mathrm{P}<0.05, \mathrm{P}<0.01$, Figure 5$)$.
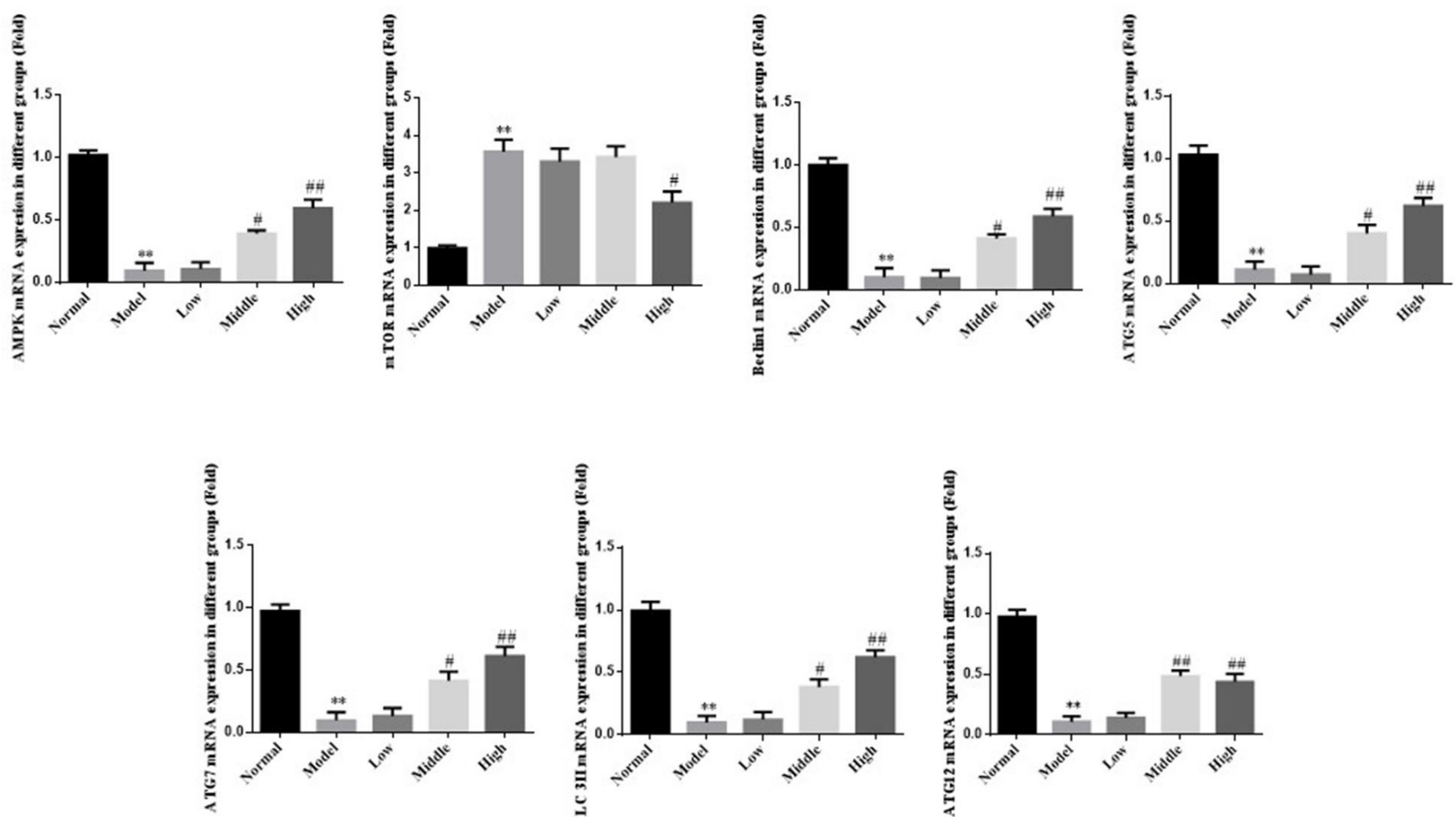


with Normal group; $\# \mathrm{P}<0.05$, \# $\mathrm{P}<0.01$, compared with Model group.



Figure 5. Effect of ECA on the protein expression levels of autophagy related factors in synovium of footpad joint of $\mathrm{AA}$ rats. ${ }^{* *} \mathrm{P}<0.01$, compared with Normal group; $\# \mathrm{P}<0.05, \# \# \mathrm{P}<0.01$, compared with Model group. 


\section{Discussion}

According to the experimental results of our study, ECA could significantly inhibit the proliferation of synovial tissue and inflammatory cell infiltration in AA rats, and reduce cartilage damage and fibrosis, especially by using ECA at a dosage of $100 \mathrm{mg} /$ $\mathrm{kg}$. ECA intervention could result in significantly decreased mRNA expression levels of TNF- $\alpha$, IL-1 $\beta$, IL- 6 , IL-17 and COX-2 in inflammatory synovium of AA rats. Meanwhile, in view of the integral animal experiment, ECA could also exert an inhibitory role in the mRNA expression levels of inflammationrelated factors such as TNF- $\alpha$, IL-1 $1 \beta$, IL-6, IL-17 and COX-2. Collectively, findings in our study suggest that ECA can inhibit the inflammatory response of AA rats.

In general, owing to the insufficient glycolytic enzyme of enzyme fructose-6-phosphate, 2-Kinase/fructose-2,6bisphosphatase, RA patients may have low glycolytic flux in T cells and ATP deficiency in vivo (Silva et al., 2019; Custers et al., 2007). It may further reduce the ratio of AMP to ATP, activate the autophagy-related AMPK-PI3K-mTOR signal transduction pathway in patients, and result in the abnormal expressions of genes and proteins related to this pathway (Luo et al., 2018; Larabi et al., 2020; Wang et al., 2019; Hwang et al., 2020). Importantly, AMPK and mTOR are the key genes and proteins to activate the autophagy pathway within the AMPK-PI3K-mTOR signal transduction pathway. Accordingly, it is suggested that the abnormal autophagy pathway in RA patients may be one of the causes explaining the pathogenesis of RA.

Autophagy has been recognized to play a role in maintaining the intracellular environment stability by degrading long-lived proteins and damaged organelles (Lamark et al., 2017; Kim \& Lee, 2014). Macroautophagy is the main form of autophagy, especially the cell biological pathway regulated by autophagy related gene ATG. The autophagic bodies are generally formed at the contact point between endoplasmic reticulum and mitochondria. Two ubiquitin-like conjugated systems (ATG12 and ATG8/LC3II) extend the double-membrane autophagic body to a part of the cytoplasm on the basis of the microtubule-dependent track that interacts and fuses with the lysosome. Furthermore, AMPK can activate and promote the production of unc-51-like kinase complex, block the production of mTOR and hence stimulate autophagy. Meanwhile, unc-51-like kinase complex can further boost the production of Beclin1, then activate the production of autophagic bodies, and further advance the production of LC3-II. In this process, ATG7 acts as an E1-like ubiquitin activator to activate ATG12; and the activated ATG12 is then delivered to E2-like ubiquitin transferase. Ultimately, ATG12 and ATG5 interact to form a complex with the ability to promote the combination of autophagosomes and lysosomes to stimulate the binding of the transported substances to lysosomes, which are then decomposed and reused by cells (Li \& Zhang, 2019; Shibutani et al., 2015). In this regard, there may be a cascade relationship among ATG5, ATG7 and ATG12, which may not be completely consistent at the transcription and translation levels. In our experiment, there were differences in the mRNA and protein expressions of ATG5 and ATG7 in the Normal group and the Model group. The proposed difference nay be related to this cascade mechanism of gene expression in AA rat model.
Similarly, relevant reports also confirmed the same difference during the construction of rat model (ten Bokum et al., 1999; Kim \& Moudgil, 2009). However and importantly, it produced no significant impact on gene expression, which may be explained by the synthesis and expression of autophagy related genes in AA rat model. Furthermore, our study also revealed that ECA could increase the expression level of AMPK and inhibit the expression level of mTOR, an autophagy negative regulatory protein. Simultaneously, the intervention could also increase the expression levels of Beclin1 and LC3-II that were cascaded with AMPK. Moreover, there was also an obvious upregulation in the expression levels of ATG5, ATG7 and ATG12, which regulate the binding of autophagosomes to lysosomes. Collectively, ECA may have a promoting effect on cell autophagy in inflamed synovium of AA rats.

\section{Conclusion}

In conclusion, ECA has a therapeutic effect on the inflammatory response of AA rats induced by CFA. It may be related to its promoting role in the level of autophagy in inflammatory synovium of AA rats. Findings in our study may provide an experimental basis for further study on the anti-inflammatory effect and mechanism of ECA.

\section{References}

Chen, X.-D., Tang, J.-J., Feng, S., Huang, H., Lu, F.-N., Lu, X.-M., \& Wang, Y.-T. (2021). Chlorogenic acid improves PTSD-like symptoms and associated mechanisms. Current Neuropharmacology, 19. http:// dx.doi.org/10.2174/1570159X19666210111155110. PMid:33430733.

Custers, R. J. H., Creemers, L. B., Verbout, A. J., van Rijen, M. H. P., Dhert, W. J. A., \& Saris, D. B. F. (2007). Reliability, reproducibility and variability of the traditional Histologic/Histochemical Grading System vs the new OARSI Osteoarthritis Cartilage Histopathology Assessment System. Osteoarthritis and Cartilage, 15(11), 1241-1248. http://dx.doi.org/10.1016/j.joca.2007.04.017. PMid:17576080.

Hao, S., Xiao, Y., Lin, Y., Mo, Z., Chen, Y., Peng, X., Xiang, C., Li, Y., \& Li, W. (2016). Chlorogenic acid-enriched extract from Eucommia ulmoides leaves inhibits hepatic lipid accumulation through regulation of cholesterol metabolism in HepG2 cells. Pharmaceutical Biology, 54(2), 251-259. http://dx.doi.org/10.3109/13880209.2015.102905 4. PMid:25845641.

Hwang, H.-Y., Shim, J. S., Kim, D., \& Kwon, H. J. (2020). Antidepressant drug sertraline modulates AMPK-MTOR signaling-mediated autophagy via targeting mitochondrial VDAC1 protein. Autophagy. In press. http://dx.doi.org/10.1080/15548627.2020.1841953. PMid:33124469.

Jiang, Y., Nan, H., Shi, N., Hao, W., Dong, J., \& Chen, H. (2021). Chlorogenic acid inhibits proliferation in human hepatoma cells by suppressing noncanonical NF-kappaB signaling pathway and triggering mitochondrial apoptosis. Molecular Biology Reports, 48(3), 2351-2364. http://dx.doi.org/10.1007/s11033-021-06267-3. PMid:33738723.

Kim, E. Y., \& Moudgil, K. D. (2009). The determinants of susceptibility/ resistance to adjuvant arthritis in rats. Arthritis Research \& Therapy, 11(4), 239. http://dx.doi.org/10.1186/ar2755. PMid:19678912.

Kim, K. H., \& Lee, M. S. (2014). Autophagy: a key player in cellular and body metabolism. Nature Reviews. Endocrinology, 10(6), 322337. http://dx.doi.org/10.1038/nrendo.2014.35. PMid:24663220. 
Lamark, T., Svenning, S., \& Johansen, T. (2017). Regulation of selective autophagy: the p62/SQSTM1 paradigm. Essays in Biochemistry, 61(6), 609-624. http://dx.doi.org/10.1042/EBC20170035. PMid:29233872.

Larabi, A., Barnich, N., \& Nguyen, H. T. T. (2020). New insights into the interplay between autophagy, gut microbiota and inflammatory responses in IBD. Autophagy, 16(1), 38-51. http://dx.doi.org/10.10 80/15548627.2019.1635384. PMid:31286804.

Li, W., \& Zhang, L. (2019). Regulation of ATG and Autophagy Initiation. Advances in Experimental Medicine and Biology, 1206, 41-65. http:// dx.doi.org/10.1007/978-981-15-0602-4_2. PMid:31776979.

Luo, G., Cheng, B. C.-Y., Zhao, H., Fu, X.-Q., Xie, R., Zhang, S.-F., Pan, S.-Y., \& Zhang, Y. (2018). Schisandra chinensis lignans suppresses the production of inflammatory mediators regulated by NF- $\kappa B$, AP-1, and IRF3 in lipopolysaccharide-stimulated RAW264.7 cells. Molecules, 23(12), 3319. http://dx.doi.org/10.3390/molecules23123319. PMid:30558163.

Murakami, S., Tasaka, Y., Takatori, S., Tanaka, A., Kawasaki, H., \& Araki, H. (2018). Effect of Eucommia ulmoides leaf extract on chronic dextran sodium sulfate-induced colitis in mice. Biological \& Pharmaceutical Bulletin, 41(6), 864-868. http://dx.doi.org/10.1248/ bpb.b17-00878. PMid:29863075.

Shibutani, S. T., Saitoh, T., Nowag, H., Münz, C., \& Yoshimori, T. (2015). Autophagy and autophagy-related proteins in the immune system. Nature Immunology, 16(10), 1014-1024. http://dx.doi.org/10.1038/ ni.3273. PMid:26382870.

Silva, J. L. G., Passos, D. F., Bernardes, V. M., \& Leal, D. B. R. (2019). ATP and adenosine: role in the immunopathogenesis of rheumatoid arthritis. Immunology Letters, 214, 55-64. http:// dx.doi.org/10.1016/j.imlet.2019.08.009. PMid:31479688.

ten Bokum, A. M., Lichtenauer-Kaligis, E. G., Melief, M. J., van Koetsveld, P. M., Bruns, C., van Hagen, P. M., Hofland, L. J., Lamberts, S. W., \& Hazenberg, M. P. (1999). Somatostatin receptor subtype expression in cells of the rat immune system during adjuvant arthritis. The Journal of Endocrinology, 161(1), 167-175. http://dx.doi.org/10.1677/ joe.0.1610167. PMid:10194540.

Teng, Z., Wang, L., Du, H., Yang, G., Fu, T., Lian, H., Sun, Y., Liu, S., Zhang, L., \& Gao, T. (2021). Metabolomic and lipidomic approaches to evaluate the effects of Eucommia ulmoides leaves on milk quality and biochemical properties. Frontiers in Veterinary Science, 8, 644967. http://dx.doi.org/10.3389/fvets.2021.644967. PMid:34141731.

van Eden, W., Wagenaar-Hilbers, J. P., \& Wauben, M. H. (2001). Adjuvant arthritis in the rat. Current Protocols in Immunology, Chapter 15, 4. http://dx.doi.org/10.1002/0471142735.im1504s19. PMid:18432736.

Wang, H., Liu, Y., Wang, D., Xu, Y., Dong, R., Yang, Y., Lv, Q., Chen, X., \& Zhang, Z. (2019). The upstream Pathway of mTOR-mediated autophagy in liver diseases. Cells, 8(12), 1597. http://dx.doi.org/10.3390/ cells8121597. PMid:31835352.

Wang, J.-Y., Chen, X.-J., Zhang, L., Pan, Y.-Y., Gu, Z.-X., He, S.-M., Song, Z.-P., \& Yuan, Y. (2018). Comparative studies of different extracts from Eucommia ulmoides Oliv. against rheumatoid arthritis in CIA rats. Evidence-Based Complementary and Alternative Medicine, 2018, 7379893. http://dx.doi.org/10.1155/2018/7379893. PMid:30105062.

Wasserman, A. M. (2011). Diagnosis and management of rheumatoid arthritis. American Family Physician, 84(11), 1245-1252. PMid:22150658.

Weng, W., Wang, F., He, X., Zhou, K., Wu, X., \& Wu, X. (2021). Protective effect of Corynoline on the CFA induced Rheumatoid arthritis via attenuation of oxidative and inflammatory mediators. Molecular and Cellular Biochemistry, 476(2), 831-839. http://dx.doi.org/10.1007/ s11010-020-03948-8. PMid:33174074.

Weyand, C. M., \& Goronzy, J. J. (2021). The immunology of rheumatoid arthritis. Nature Immunology, 22(1), 10-18. http://dx.doi.org/10.1038/ s41590-020-00816-x. PMid:33257900.

Xing, Y.-Y., Wang, J.-Y., Wang, K., Zhang, Y., Liu, K., Chen, X.-Y., \& Yuan, Y. (2020). Inhibition of rheumatoid arthritis using bark, leaf, and male flower extracts of Eucommia ulmoides. Evidence-Based Complementary and Alternative Medicine, 2020, 3260278. http:// dx.doi.org/10.1155/2020/3260278. PMid:32855647.

Zhou, J., Zhang, F., Chen, J., Zhang, S., \& Wang, H. (2021). Chlorogenic acid inhibits human glioma U373 Cell progression via regulating the SRC/MAPKs signal pathway: based on network pharmacology analysis. Drug Design, Development and Therapy, 15, 1369-1383. http://dx.doi.org/10.2147/DDDT.S296862. PMid:33833498. 